\title{
Left ventricular performance of pulmonary atresia with intact ventricular septum after right heart bypass surgery
}

Yoshihisa Tanoue, MD

Hideaki Kado, MD

Taketoshi Maeda, MD

Yuichi Shiokawa, MD

Naoki Fusazaki, MD

Shiro Ishikawa, MD

From the Departments of Cardiovascular Surgery and Pediatric Cardiology, Fukuoka Children's Hospital Medical Center, Fukuoka, Japan.

Read at the Eighty-fourth Annual Meeting of The American Association for Thoracic Surgery, Toronto, Ontario, Canada, April 25-28, 2004.

Received for publication April 21, 2004; revisions received July 17, 2004; accepted for publication July 22, 2004.

Address for reprints: Yoshihisa Tanoue, MD, Department of Cardiovascular Surgery, Kyushu University, 3-1-1 Maidashi, Higashi-ku, Fukuoka 812-8582, Japan (Email: tanoue@heart.med.kyushu-u.ac.jp).

J Thorac Cardiovasc Surg 2004;128:710-7

$0022-5223 / \$ 30.00$

Copyright (c) 2004 by The American Association for Thoracic Surgery

doi:10.1016/j.jtcvs.2004.07.035
Objective: The left ventricular performance in patients with pulmonary atresia with intact ventricular septum who were Fontan candidates before and after the bidirectional Glenn procedure and a staged total cavopulmonary connection was compared with that in patients with tricuspid atresia.

Methods: Contractility (end-systolic elastance), afterload (effective arterial elastance), and ventricular efficiency (ventriculoarterial coupling, arterial elastance/endsystolic elastance ratio), and the ratio of stroke work and pressure-volume area were approximated on the basis of cardiac catheterization data before the bidirectional Glenn procedure, before and after staged total cavopulmonary connection, and approximately 1 year after the completion of total cavopulmonary connection in 20 patients with pulmonary atresia with intact ventricular septum and 21 patients with tricuspid atresia.

Results: The end-systolic elastance of the pulmonary atresia with intact ventricular septum group was significantly inferior to that of the tricuspid atresia group after bidirectional Glenn procedure and total cavopulmonary connection (1 year after total cavopulmonary connection $1.85 \pm 0.51 \mathrm{~mm} \mathrm{Hg} \cdot \mathrm{m}^{2} \cdot \mathrm{mL}^{-1}$ vs $2.84 \pm 0.96$ $\left.\mathrm{mm} \mathrm{Hg} \cdot \mathrm{m}^{2} \cdot \mathrm{mL}^{-1}, P<.01\right)$. The arterial elastance was not different between groups throughout the assessment period and tended to increase in a stepwise fashion after bidirectional Glenn procedure and total cavopulmonary connection. The arterial elastance/end-systolic elastance ratio and ratio of stroke work and pressure-volume area of the pulmonary atresia with intact ventricular septum group tended to worsen, whereas those of the tricuspid atresia group tended to improve. The difference reached statistical significance 1 year after total cavopulmonary connection $(1.15 \pm 0.35$ vs $0.82 \pm 0.23$ and $64.2 \% \pm 6.7 \%$ vs $71.3 \% \pm 5.7 \%$, respectively, $P<.05$ and $P<.05$, respectively).

Conclusion: The contractility and ventricular efficiency of patients with pulmonary atresia with intact ventricular septum are inferior to those of patients with tricuspid atresia after bidirectional Glenn procedure and total cavopulmonary connection. A high-pressure residual right ventricle may impair the left ventricular performance of patients with pulmonary atresia with intact ventricular septum after bidirectional Glenn procedure and total cavopulmonary connection.

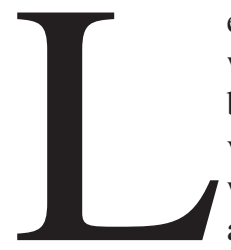

eft ventricular (LV) performance in patients with pulmonary atresia with intact ventricular septum (PA/IVS) is of crucial significance because the tricuspid valve and right ventricle (RV) of such individuals are hypoplastic to varying degrees. The treatment of patients with PA/IVS is dictated by the size of the tricuspid annulus, the size and shape of the RV, and the presence of coronary artery obstructive lesions. In patients with severe hypoplasia of the tricuspid valve and RV, the Fontan 
procedure is used to separate the systemic and pulmonary circulations, thereby eliminating arterial hypoxemia and ventricular volume overloading. ${ }^{1-11}$ In patients with PA/ IVS, the sole pumping chamber of Fontan candidates is the left-dominant ventricle, which is considered more suitable as a systemic pumping chamber than the right-dominant single ventricle. However, LV function in patients with PA/IVS is not always as good as expected.

We hypothesize that the detail analysis of the interplay between contractility and afterload provided by end-systolic elastance (Ees), effective arterial elastance (Ea), ventriculoarterial coupling (Ea/Ees), and the ratio of stroke work and pressure-volume area (SW/PVA) manifests the impaired LV performance in patients with PA/IVS. In this study, the LV performances of patients with PA/IVS before and after the bidirectional Glenn procedure (BDG) and a staged total cavopulmonary connection (TCPC) were compared with those of patients with tricuspid atresia (TA). TA is also a single-ventricle disease that affects the left-dominant ventricle. The purpose of this study was to analyze the LV performance (contractility, afterload, ventricular efficiency) of patients with PA/IVS who had undergone right heart bypass surgery.

\section{Patients and Methods \\ Patient Information}

Twenty consecutive patients with PA/IVS (10 male and 10 female) and 21 consecutive patients with TA (11 male and 10 female) underwent both BDG and TCPC at the Fukuoka Children's Hospital Medical Center between November 1992 and May 2003. The patients were operated on during the same period, and no operative or in-hospital deaths were seen. Informed consent for both the operation and cardiac catheterization was obtained from the parents of all children.

In the PA/IVS group, coronary artery obstructive lesions in association with the RV-coronary artery fistulas were present in $6 \mathrm{pa}-$ tients, mitral regurgitation was present in 4 , and paroxysmal supraventricular tachycardia was present in 1 . In the TA group, the ventriculoarterial connections were concordant in 20 patients and discordant in 1, mitral regurgitation was present in 2, partial anomalous pulmonary venous return was present in 1 , and an aortopulmonary window was present in 1 . Before BDG, a systemic-to-pulmonary shunt was performed in 29 patients (20 patients with PA/IVS and 9 patients with TA), and pulmonary artery banding was performed in 7 of the patients with TA. Mean ages of the patients with PA/IVS were $37.9 \pm 37.7$ months (6-142 months) at BDG and $60.8 \pm 36.2$ months (25-153 months) at TCPC. Mean weights at these procedures were $10.3 \pm 5.0 \mathrm{~kg}(5.1-22.6 \mathrm{~kg})$ and $14.3 \pm 4.9 \mathrm{~kg}(8.4-29.7 \mathrm{~kg})$, respectively. Mean ages of the patients with TA were $41.6 \pm 38.4$ months (6-129 months) at BDG and 64.2 \pm 35.9 months (27-142 months) at TCPC. The mean weights at these procedures were $11.9 \pm$ $6.5 \mathrm{~kg}(5.8-27.5 \mathrm{~kg})$ and $15.6 \pm 6.7 \mathrm{~kg}(9.2-33.6 \mathrm{~kg})$, respectively.

\section{Operative Techniques}

Anesthesia was conducted by a standard technique with intravenous infusions of fentanyl, inhalation of sevoflurane, and muscle relaxation with pancuronium. Aortic and bicaval cannulations were performed through a standard median sternotomy, and cardiopulmonary bypass (CPB) was instituted with a heart-lung machine consisting of a rotating pump and a membrane oxygenator. When heart arrest was necessary, myocardial preservation was achieved with a cold crystalloid cardioplegic solution ${ }^{12,13}$ combined with topical cooling. In the patients with PA/IVS with coronary artery obstructive lesions in association with the RVcoronary artery fistulas, the central venous pressure was kept high to avoid decompressing the RV during $\mathrm{CPB}$ with a beating heart, and cardioplegic heart arrest was induced immediately after the introduction of CPB if heart arrest was necessary.

$\boldsymbol{B D G}$. Bidirectional cavopulmonary shunts were made by direct end-to-side anastomosis between the superior vena cava and the pulmonary artery. Bilateral superior venae cavae were present in 2 of the patients with TA, and bidirectional cavopulmonary anastomoses were conducted separately. With respect to concomitant procedures, augmentation of the pulmonary artery was performed in 17 patients ( 8 with PA/IVS and 9 with TA), mitral valvuloplasty was performed in 6 (4 with PA/IVS and 2 with TA), and an enlargement of atrial septal defect was performed in 20 (13 with PA/IVS and 7 with TA). Additional pulmonary blood flow was maintained in 7 patients with PA/IVS (all systemic-to-pulmonary shunt) and 15 with TA (5 systemic-to-pulmonary shunts and 10 main pulmonary arteries). Mean CPB time of the patients with PA/IVS was $95.5 \pm 49.3$ minutes (33-148 minutes), and that of the patients with TA was $98.0 \pm 37.8$ minutes (32-154 minutes). Mean aortic crossclamp time of the patients with PA/IVS was $6.1 \pm 11.9$ minutes $(0-41$ minutes), and that of the patients with TA was $6.0 \pm 13.6$ minutes (0-44 minutes).

TCPC. For inferior cavopulmonary anastomoses, the lateral tunnel technique ${ }^{14}$ was performed in 1 patient with PA/IVS and 3 patients with TA, and the extracardiac conduit approach with a 16 - to 20 -mm polytetrafluoroethylene graft $^{15}$ was performed in 19 patients with PA/IVS and 18 patients with TA. Fenestration was not created in any patient. Augmentation of the pulmonary artery was performed in 12 patients ( 4 with PA/IVS and 8 with TA), mitral valvuloplasty was performed in 2 (1 from each group), an enlargement of atrial septal defect was performed in 3 ( 2 with PA/IVS and 1 with TA), and release of pulmonary venous obstruction was performed in 1 patient with TA. Mean CPB time of the patients with PA/IVS was $78.6 \pm$ 28.0 minutes (39-130 minutes), and that of the patients with TA was $98.9 \pm 39.3$ minutes (42-206 minutes). Mean aortic crossclamp time of the patients with PA/IVS was $5.4 \pm 14.1$ minutes (0-45 minutes), and that of the patients with TA was $9.6 \pm 14.8$ minutes (0-47 minutes).

\section{Data Analysis}

All patients underwent cardiac catheterization before BDG (PreG) and before and after TCPC (PreT, Post $\mathrm{T}_{0}$ ), and 35 patients (19 with PA/IVS and 16 with TA) similarly underwent cardiac catheterization approximately 1 year after TCPC (Post $\left.\mathrm{T}_{1}\right)$. Biplane left ventriculography was performed, and LV volumes were calculated with the area-length method. ${ }^{16} \mathrm{RV}$ volume was excluded in both groups as a unified method. Calculations of the percentage of normal LV end-diastolic volume (\%N-EDV) were conducted on the basis of control data obtained from patients matched by body 

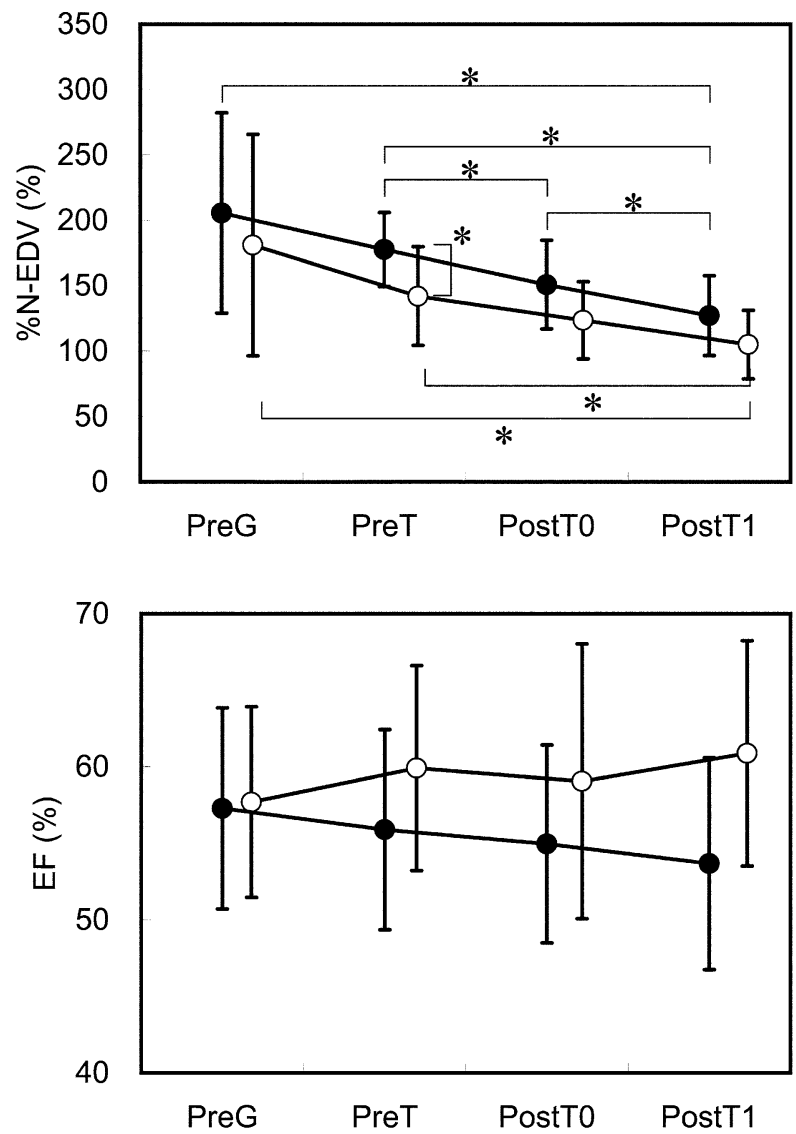

Figure 1. Time courses of \%N-EDV and LVEF. \%N-EDV in PA/IVS group tended to be larger than that in TA group, and it decreased stepwise in both groups after BDG and TCPC. LVEF in PA/IVS group was lower than that in TA group. Black circles represent mean values of PA/IVS group; open circles represent mean values of TA group; error bars represent SD. Asterisk indicates $P<.05$ by Bonferroni test.

surface area who underwent follow-up cardiac catheterization after treatment for Kawasaki disease with intact coronary artery at Fukuoka Children's Hospital Medical Center. LV ejection fraction (LVEF) was calculated as follows: $\mathrm{LVEF}=(1-$ minimal $\mathrm{LV}$ volume/maximal $\mathrm{LV}$ volume $\times 100 \%$. The calculations of contractility (Ees), afterload (Ea), and ventricular efficiency (Ea/Ees and SW/PVA) were performed on the basis of pressure and volume data obtained from cardiac catheterization by the approximation method, as previously described elsewhere. ${ }^{17-19}$ Approximations of Ees and Ea were performed as follows: Ees = mean arterial pressure/minimal $\mathrm{LV}$ volume, and $\mathrm{Ea}=\operatorname{maximal} \mathrm{LV}$ pressure/(maximal LV volume - minimal LV volume). LV volume was divided by the body surface area. Ea/Ees represents the ventriculoarterial coupling between the LV and arterial system described by Burkhoff and Sagawa. ${ }^{20}$ SW/PVA was calculated as follows: SW/PVA $=1 /(1+0.5 \mathrm{Ea} /$ Ees $) \times 100 \%$. This theoretic formula was previously described by Nozawa and colleagues. $^{21}$
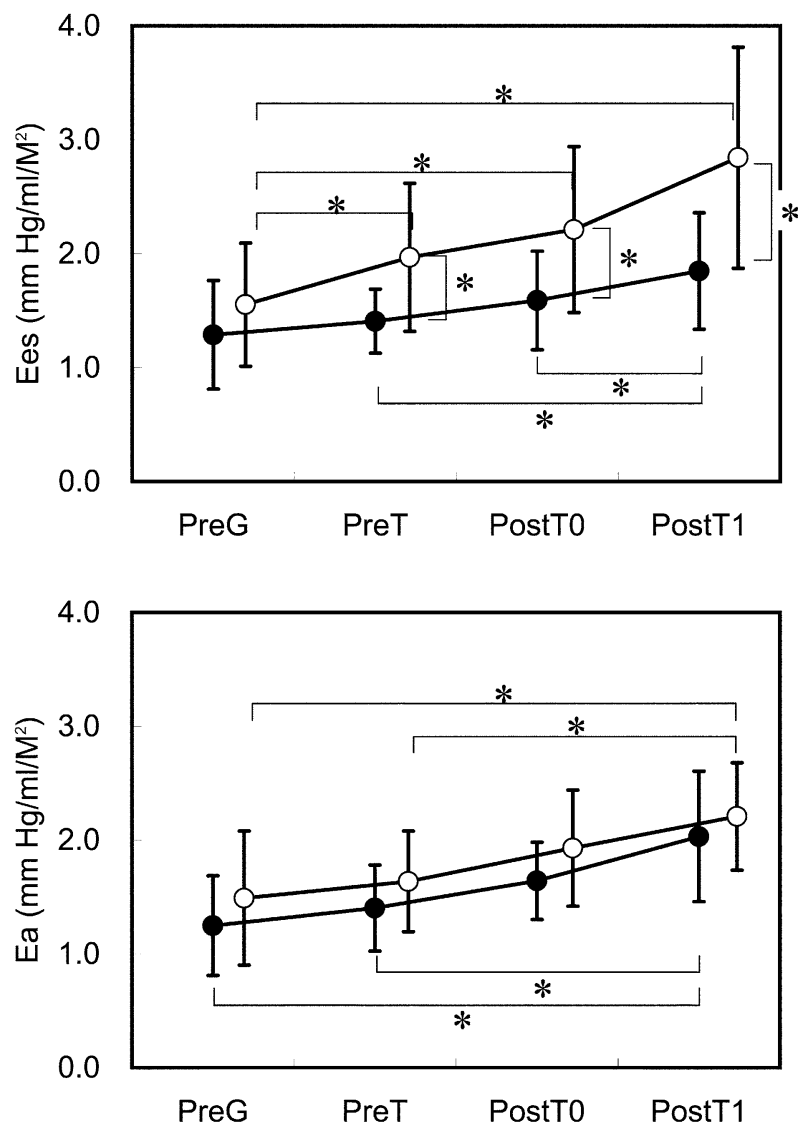

Figure 2. Time courses of Ees and Ea. Ees in PA/IVS group was significantly lower than that in TA group. Although Ees was not different between groups before BDG and improved stepwise in both groups after BDG and TCPC, Ees in PA/IVS group was significantly inferior to that in TA group after BDG and TCPC. Ea was not different between groups throughout assessment period and increased stepwise after BDG and TCPC. Black circles represent mean values of $\mathrm{PA} / \mathrm{IVS}$ group; open circles represent mean values of TA group; error bars represent SD. Asterisk indicates $P$ $<.05$ by Bonferroni test.

\section{Statistical Analysis}

The results are presented as mean \pm SD. Two-factor analysis of variance with repeated measures of one factor (RM-ANOVA) was used for the measured variables of PreG, PreT, Post $\mathrm{T}_{0}$, and Post $\mathrm{T}_{1}$ (4 points). The analysis clarified whether each of the repeated measures and nonrepeated factors were significantly different among or between levels, and also whether interactions between the two factors were significant. This analysis was used to determine whether the variables were statistically different among the four time points and between patients with PA/IVS and patients with TA. The Bonferroni test was used as a post hoc test.

\section{Results}

Hemodynamic variables (mean pulmonary arterial pressure, mean aortic pressure, Nakata pulmonary arterial index, ${ }^{22}$ 
systemic arterial oxygen saturation, and atrioventricular valve regurgitation) during cardiac catheterization before and after BDG and TCPC are shown in Table 1. Mean pulmonary arterial pressure in the PA/IVS group was significantly lower than in the TA group $(P=.016$ by RMANOVA), and in both groups it decreased in a stepwise fashion ( $P<.001$ by RM-ANOVA). There was no statistically significant difference between the two groups in mean aortic pressure, pulmonary arterial index, and systemic arterial oxygen saturation. Mean aortic pressure and systemic arterial oxygen saturation increased after TCPC in a stepwise manner $(P<.001$ and $P<.001$, respectively, by RM-ANOVA).

The time courses of \%N-EDV, LVEF, Ees, Ea, Ea/Ees, and SW/PVA in both groups are shown in Figures 1, 2, and 3 . The $\% \mathrm{~N}-\mathrm{EDV}$ of the PA/IVS group tended to be larger than that of the TA group ( $P=.051$ by RM-ANOVA), and the difference between the two groups before TCPC (PreT) was statistically significant (PA/IVS group $178 \% \pm 28 \%$, TA group $142 \% \pm 37 \%, P<.05$ by Bonferroni test). In both groups, the $\% \mathrm{~N}-\mathrm{EDV}$ decreased after BDG and TCPC in a stepwise fashion $(P<.001$ by RM-ANOVA). The LVEF of the PA/IVS group was significantly lower than that of the TA group ( $P=.004$ by RM-ANOVA), and the Ees of the PA/IVS group was significantly lower than that of the TA group $(P<.001$ by RM-ANOVA). Although the Ees values of both groups were not different before BDG (PreG) and improved in a stepwise fashion after BDG and TCPC $(P<.001$ by RM-ANOVA), the Ees of the PA/IVS group was significantly inferior to that of the TA group after BDG and TCPC (PreT $1.41 \pm 0.28 \mathrm{~mm} \mathrm{Hg} \cdot \mathrm{m}^{2} \cdot \mathrm{mL}^{-1}$ vs $1.97 \pm 0.64 \mathrm{~mm} \mathrm{Hg} \cdot \mathrm{m}^{2} \cdot \mathrm{mL}^{-1}, P<.05$ by Bonferroni test, Post $\mathrm{T}_{0} 1.59 \pm 0.43 \mathrm{~mm} \mathrm{Hg} \cdot \mathrm{m}^{2} \cdot \mathrm{mL}^{-1}$ vs $2.21 \pm 0.72$ $\mathrm{mm} \mathrm{Hg} \cdot \mathrm{m}^{2} \cdot \mathrm{mL}^{-1}, P<.05$ by Bonferroni test, PostT 1 $1.85 \pm 0.51 \mathrm{~mm} \mathrm{Hg} \cdot \mathrm{m}^{2} \cdot \mathrm{mL}^{-1}$ vs $2.84 \pm 0.96 \mathrm{~mm} \mathrm{Hg}$. $\mathrm{m}^{2} \cdot \mathrm{mL}^{-1}, P<.01$ by Bonferroni test). Ea was not different between the groups throughout the assessment period and increased in a stepwise fashion after BDG and TCPC ( $P<.001$ by RM-ANOVA). Differences in Ea/Ees and SW/PVA between the two groups were statistically significant $(P=.003$ and $P=.002$, respectively, by RMANOVA). The Ea/Ees and SW/PVA of the PA/IVS group tended to worsen, whereas those of the TA group tended to improve. One year after TCPC, this difference became statistically significant $\left(\right.$ Post $_{1} 1.15 \pm 0.35$ vs $0.82 \pm 0.23$, and $64.2 \% \pm 6.7 \%$ vs $71.3 \% \pm 5.7 \%$, respectively, $P<.05$ and $P<.05$, respectively, by Bonferroni test).

\section{Discussion}

The major findings of this study of patients with PA/IVS who underwent right heart bypass surgery were as follows: (1) Contractility (Ees) of patients with PA/IVS was lower than that of patients with TA after BDG and TCPC. (2)
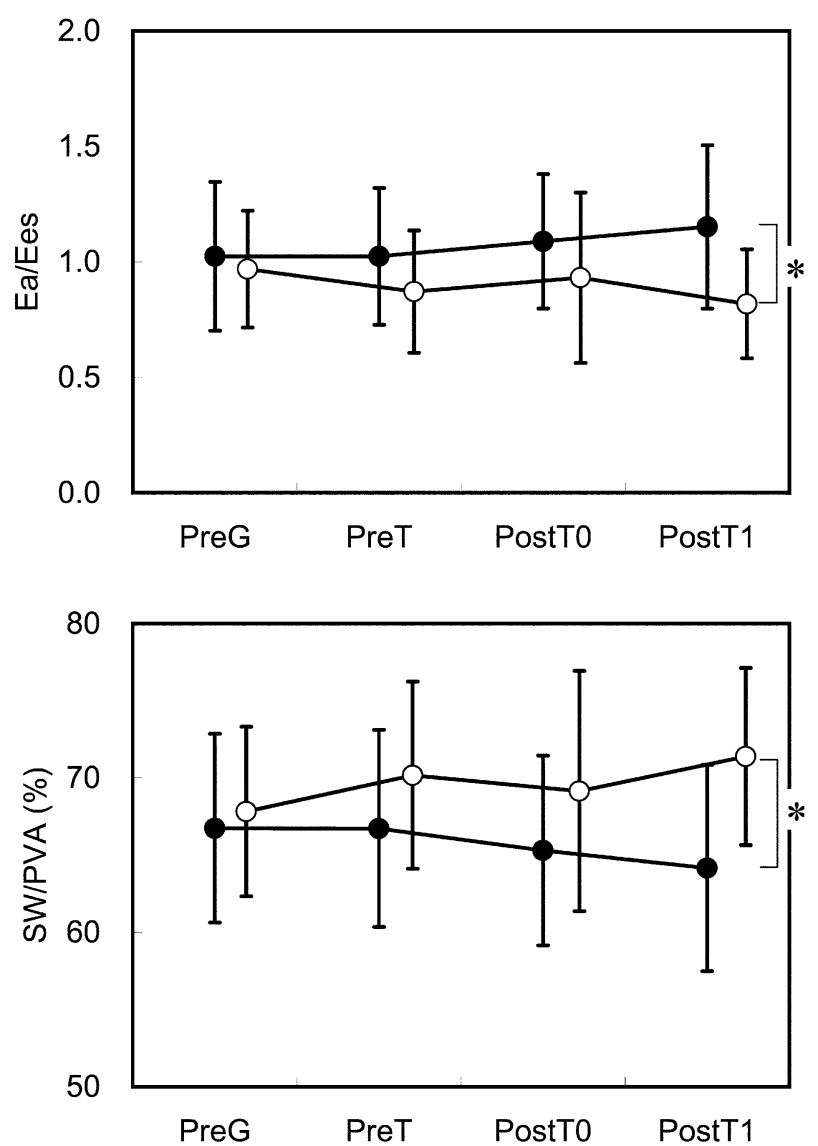

Figure 3. Time courses of Ea/Ees and SW/PVA. Differences between groups in Ea/Ees and SW/PVA were statistically significant. Ea/Ees and SW/PVA in PA/IVS group tended to worsen, whereas those in TA group tended to improve. Differences between groups became statistically significant 1 year after TCPC. Black circles represent mean values of PA/IVS group; open circles represent mean values of TA group; error bars represent SD. Asterisk indicates $\boldsymbol{P}<.05$ by Bonferroni test.

Ventricular efficiency (Ea/Ees and SW/PVA) of patients with PA/IVS was inferior to that of patients with TA after TCPC. To the best of our knowledge, this is the first report to focus on ventricular performance (contractility, afterload, ventricular efficiency) of patients with PA/IVS who are Fontan candidates.

PA/IVS is an anatomically heterogeneous congenital heart disease that shows morphologic variations in the size of the tricuspid annulus, the size and shape of the RV cavity, and coronary artery obstructive lesions in association with the RV-coronary artery fistulas. The varying degrees of these morphologic factors dictate whether patients are candidates for biventricular repair or for less corrective procedures such as the Fontan operation. Many studies on PA/ IVS have discussed these variations as an indication for surgical strategies such as biventricular repair, one-and-a- 
TABLE 1. Hemodynamic variables during cardiac catheterization

\begin{tabular}{|c|c|c|c|c|}
\hline & PreG & PreT & ${\text { Post } T_{0}}$ & PostT $_{1}$ \\
\hline \multicolumn{5}{|c|}{ Mean pulmonary arterial pressure $(\mathrm{mm} \mathrm{Hg}$, mean $\pm \mathrm{SD})$} \\
\hline PA/IVS group & $13.6 \pm 6.2$ & $8.1 \pm 2.9^{*}$ & $8.1 \pm 2.2^{*}$ & $7.3 \pm 2.7^{*}$ \\
\hline TA group & $15.7 \pm 7.2$ & $9.0 \pm 3.0^{*}$ & $8.9 \pm 2.6^{*}$ & $8.4 \pm 2.3^{*}$ \\
\hline \multicolumn{5}{|c|}{ Mean aortic pressure $(\mathrm{mm} \mathrm{Hg}$, mean $\pm \mathrm{SD})$} \\
\hline PA/IVS group & $64.0 \pm 10.1$ & $73.3 \pm 12.6$ & $71.9 \pm 11.1^{*}$ & $74.3 \pm 11.3^{*}$ \\
\hline TA group & $66.9 \pm 9.7$ & $71.6 \pm 7.9$ & $73.8 \pm 8.7$ & $81.1 \pm 10.9 *$ \\
\hline \multicolumn{5}{|c|}{ Nakata pulmonary arterial index $\left(\mathrm{mm}^{2} / \mathrm{m}^{2}\right.$, mean $\left.\pm \mathrm{SD}\right)$} \\
\hline PA/IVS group & $233 \pm 93$ & $229 \pm 66$ & $211 \pm 72$ & $203 \pm 79$ \\
\hline TA group & $275 \pm 143$ & $244 \pm 122$ & $211 \pm 71$ & $203 \pm 53$ \\
\hline \multicolumn{5}{|c|}{ Arterial oxygen saturation $(\%$, mean $\pm S D)$} \\
\hline PA/IVS group & $79.2 \pm 7.8$ & $87.1 \pm 3.2^{*}$ & $93.3 \pm 1.6^{*} \dagger$ & $94.4 \pm 1.6^{*} \dagger$ \\
\hline TA group & $80.6 \pm 6.2$ & $87.7 \pm 4.0^{*}$ & $93.9 \pm 2.0^{*} \dagger$ & $94.3 \pm 2.1^{*} \dagger$ \\
\hline \multicolumn{5}{|c|}{ At least mild mitral regurgitation (No.) } \\
\hline PA/IVS group & $2(10.0 \%)$ & $2(10.0 \%)$ & $0(0.0 \%)$ & $0(0.0 \%)$ \\
\hline TA group & $3(14.3 \%)$ & $1(4.8 \%)$ & $0(0.0 \%)$ & $0(0.0 \%)$ \\
\hline
\end{tabular}

${ }^{*} P<.05$ versus PreG by Bonferroni test.

$\dagger P<.05$ versus PreT by Bonferroni test.

half-ventricular repair, single-ventricular palliation, and heart transplantation. ${ }^{3-11}$ However, patients with markedly hypoplastic tricuspid valves and RVs or with obstructive coronary artery lesions are not candidates for biventricular repair. ${ }^{1-3}$ The possibility of patients with PA/IVS becoming Fontan candidates is also of great importance.

Coronary artery obstructive lesions in association with the RV-coronary artery fistulas are considered one of the most important factors of impaired LV function in patients with PA/IVS. These coronary abnormalities cause ischemic damage to the LV myocardium. However, LV dysfunction has been demonstrated even in patients with less severe coronary abnormalities. ${ }^{23-25}$ In this study, there was no significant difference in SW/PVA 1 year after TCPC between patients with PA/IVS with and without important $\mathrm{RV}$-coronary artery fistulas $(63.9 \% \pm 6.5 \%$ vs $64.3 \% \pm$ $7.0 \%$, respectively), although the Ees 1 year after TCPC in patients with $\mathrm{PA} / \mathrm{IVS}$ with important $\mathrm{RV}$-coronary artery fistulas tended to be inferior to that in patients with PA/IVS without coronary artery lesions $(1.54 \pm 0.41 \mathrm{~mm} \mathrm{Hg}$. $\mathrm{m}^{2} \cdot \mathrm{mL}^{-1}$ vs $1.99 \pm 0.50 \mathrm{~mm} \mathrm{Hg} \cdot \mathrm{m}^{2} \cdot \mathrm{mL}^{-1}$, statistical analysis not performed because of small number of patients). Coronary abnormalities with $\mathrm{RV}$-coronary artery fistulas are, however, not always the main reasons for LV functional disturbances in patients with PA/IVS. Histologic abnormalities of the LV myocardium, cell swelling and increased interstitial fibrosis, have been demonstrated not only in patients with PA/IVS with normal coronary arteries but also in patients with TA. ${ }^{26-29}$ Small RVs were a consistent feature in patients who had PA/IVS and were Fontan candidates and in patients with TA; however, RV pressure was significantly different between the two groups. Ventricular septum interactions between the RV and the LV greatly influence LV performance. ${ }^{30,31}$ High-pressure RVs oppress the ventricular septum and then disturb LV function. Although many questions remain unanswered regarding the exact mechanisms of impaired LV function in patients with PA/IVS after right heart bypass surgery, a high-pressure RV might impair LV performance in patients with PA/IVS after BDG and TCPC. Recently, we have performed RV outflow tract reconstruction at $\mathrm{BDG}$ to decompress the highpressure RV in a patient with PA/IVS who was a Fontan candidate and did not have any RV-coronary artery fistulas.

Measurements of ordinary hemodynamic variables, such as mean aortic pressure and LVEF, are not sufficient for assessing ventricular function. Ees is a load-independent parameter of systolic ventricular function and an ideal index of contractility. However, it is difficult (practically impossible) to measure the LV pressure-volume relations that are needed to calculate Ees in clinical situations. We previously reported approximations of Ees and Ea and validated this approximation in a canine right heart bypass model with a conductance catheter in the LV cavity. ${ }^{17,32}$ This approximation was combined with cardiac catheterization data from single-ventricle patients, and then the ventricular performance of the patients who underwent right heart bypass surgery was analyzed. ${ }^{17,18}$ With this simple approximation, single LV contractility, afterload, and efficiency in patients with PA/IVS and patients with TA could be evaluated from the conventional cardiac catheterization data used in this study.

In our hospital, all Fontan candidates, not only high-risk candidates such as those with hypoplastic left heart syndrome, undergo the staged Fontan procedure. The advantages of this procedure are as follows: (1) preservation of ventricular function by relieving the volume load on the 
single ventricle at an early stage ${ }^{33,34}$; (2) prevention of myocardial hypertrophy and fibrosis ${ }^{35}$; (3) avoidance of deleterious effects as a result of a sudden decrease in ventricular volume ${ }^{35}$; (4) minimization of afterload mismatch caused by cavopulmonary anastomosis ${ }^{17}$; and (5) correction of afterload mismatch during the interval between BDG and staged TCPC. ${ }^{18}$ BDG should be performed in an early stage to prevent myocardial hypertrophy and fibrosis. ${ }^{36}$ In this study, however, the mean age at BDG was around 3 years, and that at TCPC was about 5 years. The reason for the high averages is that the study includes cases from relatively early in our experience. Recently, we began performing BDG at an early stage insofar as possible. Several strategies were considered to improve the clinical results of singleventricle patients, and the following strategies were pursued: (1) As far as possible, any concomitant procedures were finished during the BDG operation, and inferior cavopulmonary anastomosis was only performed in patients undergoing staged TCPC. (2) As far as possible, a staged Fontan procedure with an extracardiac conduit was performed with a beating heart. ${ }^{37}$ (3) Large doses of an $\alpha$-blocking agent (chlorpromazine at $1-2 \mathrm{mg} / \mathrm{kg}$ ) were used during $\mathrm{CPB},{ }^{38}$ and a $2-\mu \mathrm{g} /(\mathrm{kg} \cdot \mathrm{min})$ infusion of nitroglycerin and inhalation of $100 \%$ oxygen with 5 to $20 \mathrm{ppm}$ nitric oxide were performed on weaning from $\mathrm{CPB} .{ }^{39}$ (4) Longterm oral intakes of an angiotensin-converting enzyme inhibitor or $\beta$-blocker were adopted as an afterload-reducing therapy. These strategies during right heart bypass surgery are thought to improve the clinical results and long-term outcomes of Fontan candidates.

We clearly demonstrated impaired LV performance in patients with PA/IVS after BDG and TCPC. Nevertheless, these findings have some limitations. First, the approximation of Ees and Ea in this study has inherent limitations and is not equivalent to the measurement by conductance catheter. This study was designed to apply the concepts of Ees, $\mathrm{Ea}$, and $\mathrm{Ea} / \mathrm{Ees}$ to the patients with PA/IVS and patients with TA by using the conventional cardiac catheterization data before and after the right heart bypass surgery. We believe that the problem of the approximation in this study does not detract from the validity of our conclusions. Second, correlation of LV performance and RV-coronary artery fistulas in patients with PA/IVS should be analyzed. However the detail analysis could not be performed in this study group because of our small number of patients. In this study, there was no significant difference in LV performance between patients with PA/IVS with and without important RV-coronary artery fistulas after right heart bypass surgery. Further comparative studies of patients with PA/IVS with and without important RV-coronary artery are therefore needed. Finally, the long-term changes of LV performance (Ees, Ea, Ea/Ees, and SW/PVA) are the next important area to address. We worry about the poor long- term outcome in LV performance we saw in patients with PA/IVS who underwent right heart bypass surgery.

In conclusion, contractility and ventricular efficiency of patients with PA/IVS are inferior to those of patients with TA after BDG and TCPC. Ischemic damage of the LV myocardium as a result of coronary artery obstructive lesions in association with the RV-coronary artery fistulas is an important factor in, but is not always the main reason for, impaired LV performance in patients with PA/IVS. A highpressure residual RV might impair LV performance in patients with PA/IVS after BDG and TCPC. Before any definitive conclusions can be made, however, long-term evaluations of LV performance in patients with PA/IVS remain to be performed in future follow-up studies.

This study was prepared in consultation with Tomomi Yamada, MS, Department of Medical Information Science Kyushu University Hospital, for statistical analyses.

\section{References}

1. Mair DD, Julsrud PR, Puga FJ, Danielson GK. The Fontan procedure for pulmonary atresia with intact ventricular septum: operative and late results. J Am Coll Cardiol. 1997;29:1359-64.

2. Najm HK, Williams WG, Coles JG, Rebeyka IM, Freedom RM. Pulmonary atresia with intact ventricular septum: results of the Fontan procedure. Ann Thorac Surg. 1997;63:669-75.

3. Bichell DP. Evaluation and management of pulmonary atresia with intact ventricular septum. Curr Opin Cardiol. 1999;14:60-6.

4. Daubeney PE, Delany DJ, Anderson RH, Sandor GG, Slavik Z, Keeton BR, et al. Pulmonary atresia with intact ventricular septum: range of morphology in a population-based study. J Am Coll Cardiol. 2002;39:1670-9.

5. Yoshimura N, Yamaguchi M, Ohashi H, Oshima Y, Oka S, Yoshida $\mathrm{M}$, et al. Pulmonary atresia with intact ventricular septum: strategy based on right ventricular morphology. J Thorac Cardiovasc Surg. 2003;126:1417-26.

6. Jahangiri M, Zurakowski D, Bichell D, Mayer JE, del Nido PJ, Jonas RA. Improved results with selective management in pulmonary atresia with intact ventricular septum. J Thorac Cardiovasc Surg. 1999;118: 1046-55.

7. Rychik J, Levy H, Gaynor JW, DeCampli WM, Spray TL. Outcome after operations for pulmonary atresia with intact ventricular septum. J Thorac Cardiovasc Surg. 1998;116:924-31.

8. Bull C, Kostelka M, Sorensen K, de Leval M. Outcome measures for the neonatal management of pulmonary atresia with intact ventricular septum. J Thorac Cardiovasc Surg. 1994;107:359-66.

9. Mainwaring RD, Lamberti JJ. Pulmonary atresia with intact ventricular septum. Surgical approach based on ventricular size and coronary anatomy. J Thorac Cardiovasc Surg. 1993;106:733-8.

10. Hanley FL, Sade RM, Blackstone EH, Kirklin JW, Freedom RM, Nanda NC. Outcomes in neonatal pulmonary atresia with intact ventricular septum. A multiinstitutional study. J Thorac Cardiovasc Surg. 1993;105:406-27.

11. Hawkins JA, Thorne JK, Boucek MM, Orsmond GS, Ruttenberg HD, Veasy LG, et al. Early and late results in pulmonary atresia and intact ventricular septum. J Thorac Cardiovasc Surg. 1990;100:492-7.

12. Tanoue Y, Morita S, Hisahara M, Tominaga R, Kawachi Y, Yasui H. Arresting donor hearts with extracellular-type cardioplegia prevents vasoconstriction induced by UW solution. Cardiovasc Surg. 1998;6: 622-8.

13. Kinoshita K, Oe M, Tokunaga K. Superior protective effect of lowcalcium, magnesium-free potassium cardioplegic solution on ischemic myocardium. Clinical study in comparison with St. Thomas' Hospital solution. J Thorac Cardiovasc Surg. 1991;101:695-702. 
14. Jonas RA, Castaneda AR. Modified Fontan procedure: atrial baffle and systemic venous to pulmonary artery anastomotic techniques. J Card Surg. 1988;3:91-6.

15. Marcelletti C, Corno A, Giannico S, Marino B. Inferior vena cavapulmonary artery extracardiac conduit. A new form of right heart bypass. J Thorac Cardiovasc Surg. 1990;100:228-32.

16. Dodge HT, Sandler J, Ballew DW, Lord JD Jr. The use of biplane angiocardiography for the measurement of left ventricular volume in man. Am Heart J. 1960;60:762-76.

17. Tanoue Y, Sese A, Ueno Y, Joh K, Hijii T. Bidirectional Glenn procedure improves the mechanical efficiency of a total cavopulmonary connection in high-risk Fontan candidates. Circulation. 2001; 103:2176-80

18. Tanoue Y, Sese A, Imoto Y, Joh K. Ventricular mechanics in the bidirectional Glenn procedure and a total cavopulmonary connection. Ann Thorac Surg. 2003;76:562-6.

19. Tanoue Y, Ando H, Fukumura F, Umesue M, Uchida T, Taniguchi K, et al. Ventricular energetics in endoventricular circular patch plasty for dyskinetic anterior left ventricular aneurysm. Ann Thorac Surg. 2003; 75:1205-9.

20. Burkhoff D, Sagawa K. Ventricular efficiency predicted by an analytical model. Am J Physiol. 1986;250(6 Pt 2):R1021-7.

21. Nozawa T, Yasumura Y, Futaki S, Tanaka N, Uenishi M, Suga H. Efficiency of energy transfer from pressure-volume area to external mechanical work increases with contractile state and decreases with afterload in the left ventricle of the anesthetized closed-chest dog. Circulation. 1988;77:1116-24.

22. Nakata S, Imai Y, Takanashi Y, Kurosawa H, Tezuka K, Nakazawa M, et al. A new method for the quantitative standardization of crosssectional areas of the pulmonary arteries in congenital heart diseases with decreased pulmonary blood flow. J Thorac Cardiovasc Surg. 1984;88:610-9.

23. Hausdorf G, Gravinghoff L, Keck EW. Effects of persisting myocardial sinusoids on left ventricular performance in pulmonary atresia with intact ventricular septum. Eur Heart J. 1987;8:291-6.

24. Akagi T, Benson LN, Williams WG, Trusler GA, Freedom RM. Ventriculo-coronary arterial connections in pulmonary atresia with intact ventricular septum, and their influences on ventricular performance and clinical course. Am J Cardiol. 1993;72:586-90.

25. Gentles TL, Colan SD, Giglia TM, Mandell VS, Mayer JE Jr, Sanders SP. Right ventricular decompression and left ventricular function in pulmonary atresia with intact ventricular septum. The influence of less extensive coronary anomalies. Circulation. 1993;88(5 Pt 2):II183-8.

26. Akiba T, Becker AE. Disease of the left ventricle in pulmonary atresia with intact ventricular septum. The limiting factor for long-lasting successful surgical intervention? J Thorac Cardiovasc Surg. 1994;108: 1-8.

27. Fyfe DA, Edwards WD, Driscoll DJ. Myocardial ischemia in patients with pulmonary atresia and intact ventricular septum. J Am Coll Cardiol. 1986;8:402-6.

28. Binotto MA, Higuchi Mde L, Aiello VD. Left ventricular remodeling in hearts with tricuspid atresia: morphologic observations and possible basis for ventricular dysfunction after surgery. $J$ Thorac Cardiovasc Surg. 2003;126:1026-32.

29. Ho SY, Jackson M, Kilpatrick L, Smith A, Gerlis LM. Fibrous matrix of ventricular myocardium in tricuspid atresia compared with normal heart. A quantitative analysis. Circulation. 1996;94:1642-6.

30. Fogel MA, Weinberg PM, Fellows KE, Hoffman EA. A study in ventricular-ventricular interaction. Single right ventricles compared with systemic right ventricles in a dual-chamber circulation. Circulation. 1995; 92:219-30

31. Fogel MA, Weinberg PM, Gupta KB, Rychik J, Hubbard A, Hoffman EA, et al. Mechanics of the single left ventricle: a study in ventricularventricular interaction II. Circulation. 1998;98:330-8.

32. Tanoue Y, Morita S, Hisahara M, Tominaga R, Kawachi Y, Yasui H. Influence of cyclic variation of right ventricular volume on left ventricular mechanical parameters measured with conductance catheter. Jpn Circ J. 2001;65:749-52.

33. Bridges ND, Jonas RA, Mayer JE, Flanagan MF, Keane JF, Castaneda AR. Bidirectional cavopulmonary anastomosis as interim palliation for high- risk Fontan candidates. Early results Circulation. 1990;82(5 Suppl):IV170-6.

34. Pridjian AK, Mendelsohn AM, Lupinetti FM, Beekman RH 3rd, Dick M 2nd, Serwer G, et al. Usefulness of the bidirectional Glenn procedure as staged reconstruction for the functional single ventricle. Am J Cardiol. 1993;71:959-62.

35. Masuda M, Kado H, Shiokawa Y, Fukae K, Suzuki M, Murakami E, et al. Clinical results of the staged Fontan procedure in high-risk patients. Ann Thorac Surg. 1998;65:1721-5.

36. Milanesi O, Stellin G, Colan SD, Facchin P, Crepaz R, Biffanti R, et al. Systolic and diastolic performance late after the Fontan procedure for a single ventricle and comparison of those undergoing operation at $<12$ months of age and at $>12$ months of age. Am J Cardiol. 2002;89:276-80.

37. Tokunaga S, Kado H, Imoto Y, Masuda M, Shiokawa Y, Fukae K, et al. Total cavopulmonary connection with an extracardiac conduit: experience with 100 patients. Ann Thorac Surg. 2002;73:76-80.

38. Imoto Y, Kado H, Masuda M, Yasui H. Effects of chlorpromazine as a systemic vasodilator during cardiopulmonary bypass in neonates. Jpn J Thorac Cardiovasc Surg. 2002;50:241-5.

39. Nakano T, Kado H, Shiokawa Y, Fukae K, Nishimura Y, Miyamoto K, et al. The low resistance strategy for the perioperative management of the Norwood procedure. Ann Thorac Surg. 2004;77:908-12.

\section{Discussion}

Dr David P. Bichell (San Diego, Calif). Congratulations on an excellent presentation of this important step toward understanding the complexity of single-ventricle mechanics.

With estimates of ventricular efficiency that you validated in your own previous work, you've elegantly demonstrated that, relative to a cohort of patients with TA, the PA/IVS septum group showed worsening of contractility and ventricular efficiency with time after the BDG and Fontan operations, although the groups performed quite similarly in the pre-BDG state.

I have three questions, which I'll present individually. First, can you comment on why the disparity in the function between the two groups begins only after the BDG? If the effect of the hypertensive $\mathrm{RV}$ and its interaction on the LV is a major contributing factor to the decrement in LV function, shouldn't that relationship exist before the BDG? Why would the difference evolve only years later?

Dr Tanoue. As you pointed out, ventricular septum interaction between the right and LV by hypertensive RV should occur before BDG. In this study, however, LV performance before BDG was not different between the patients with PA/IVS and the patients with TA. The influence of the high-pressure RV on the LV performance would be relatively slight in an early age and would increase with growth.

Although many questions remain unanswered regarding the exact mechanism of impaired LV function in patients with PA/IVS after right heart bypass surgery, the long-term evaluations of the LV performance in patients with PA/IVS are significantly important. We worry about the poor long-term outcome in the LV performance we saw in patients with PA/IVS who underwent right heart bypass surgery

Dr Bichell. Second, it has been shown in previous studies that in the single LV, diastolic and systolic functions normalize if the volume unloading procedure, the BDG, is performed when the patient is younger than 12 months, whereas persistent abnormalities in ventricular function exist if the volume unloading is later. It has also been shown that late exercise capacity is better in those who have volume unloading earlier. 
Your mean ages were 3 years at BDG construction and 5 years at the Fontan. Have you looked at the ventricular efficiency measurements with respect to the timing of the BDG? In other words, do patients with earlier timing fair better in ventricular function with time?

Dr Tanoue. I agree that right heart bypass surgery should be performed as early as possible. In this series, for historical reason, relatively old series were included, leading to a relatively old average age.

The preservation of the ventricular function by relieving the volume load on the single ventricles should be performed in an early stage. Recently, we have performed BDG in the early stage insofar as possible. In this series, however, only 4 patients from each group underwent BDG at younger than 12 months. So the specifications in timing of BDG and TCPC could not be examined because of our small number of patients.

Dr Bichell. Finally, you allude in the article to RV decompression in patients with PA/IVS who were on the Fontan pathway. Sano's group has published impressive improvements in LV enddiastolic dimension and stroke volume with a complete resection of the free wall of the RV in a different model of RV failure affecting the LV. In PA/IVS, however, decompression of the RV has demonstrably resulted in a worsening of LV function, presumably because of coronary compromise.

Can you comment on your experience with decompressing these little ventricles in the PA/IVS group on the Fontan pathway? What are your recommendations for decompressing them, and what have your results been?

Dr Tanoue. We think the high-pressure RV is one of the most important factors for impaired LV function in patients with PA/ IVS. But this remains only a speculation. Recently, we have performed RV outflow tract reconstruction at BDG to decompress the high-pressure RV in a patient with PA/IVS who was a Fontan candidate and did not have any RV-coronary artery fistulas.

Now, only a few patients with PA/IVS who were Fontan candidates have undergone RV outflow tract reconstruction, so we cannot truly analyze the experience and the effect of the RV decompression on LV performance in patients with PA/IVS. We do, however, recommend the decompression of the hypertensive $\mathrm{RV}$ in patients with PA/IVS at right heart bypass surgery if there's no RV-coronary artery fistula.

Dr Frank Hanley (Stanford, Calif). I'm left with a bit of uncertainty as to how your conclusions relate to the difference between PA/IVS and TA and whether there is actually some component of a relatively long-standing systemic-pulmonary arterial shunt as a factor. All your patients with PA/IVS had a rela- tively long-standing systemic-pulmonary arterial shunts. Only half of your patients with TA did. It would seem that you could eliminate that confounding variable either by comparing just the patients with shunts in the TA group with your patients with PA/IVS or alternatively by looking at just the patients with TA and comparing those with and without shunts and seeing whether there is any difference. This would eliminate a chronic systemic shunt as a factor in the depressed long-term ventricular function.

Dr Tanoue. Previous procedures before BDG is an important factor, but that analysis was not performed because of the small number of patients.

Dr Hanley. You have all the data to look at it.

Dr John E. Mayer, Jr (Boston, Mass). What technique of CPB did you use when you constructed your bidirectional cavopulmonary shunt and your Fontan total cavopulmonary anastomosis type of procedure? Did you crossclamp the aorta? If you did, what method did you use for myocardial preservation, or did you do these in beating-heart preparations?

How did you manage CPB in terms of keeping the RV full? Because I think we've anecdotally had experience that even if you don't crossclamp the aorta in patients with RV-dependent coronary circulation, if you don't keep the heart full, you can see the electrocardiograms start to change immediately as soon as you decompress the right heart by taking away the venous return. So could you elaborate on the techniques that you've used for CPB in these cases?

Dr Tanoue. In patients with PA/IVS with important coronary artery obstructive lesions in association with the RV-coronary artery fistulas, the institution of CPB is very dangerous because cardiac ischemia may occur. In our hospital, after institution of $\mathrm{CPB}$, aortic clamping is performed immediately and cardioplegia is infused. We have no experience of the ischemic problem from $\mathrm{RV}$-coronary fistulas.

Dr Mayer. I only ask because I wonder whether in the subset of patients who have RV-dependent coronary circulation the longterm worse LV function is due to the way you've handled the coronary circulation and myocardial preservation at the time of your initial operation. I think, without seeing the individual data points and the relationship of those individual patients to the patients with RV-dependent coronary circulation, that it becomes hard to understand what the impact is on the interaction of those two factors.

Dr Tanoue. In this series, there was no significant difference in SW/PVA 1 year after TCPC between patients with PA/IVS with and without important RV-coronary artery fistulas. 